\title{
Surface response to rain events throughout the West African monsoon
}

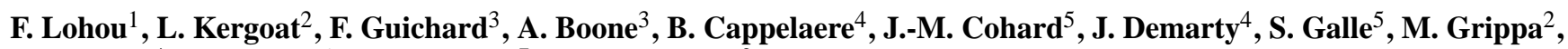 \\ C. Peugeot ${ }^{4}$, D. Ramier ${ }^{6}$, C. M. Taylor ${ }^{7}$, and F. Timouk ${ }^{2}$ \\ ${ }^{1}$ Laboratoire d'Aérologie, UMR5560, Université de Toulouse and CNRS, Toulouse, France \\ ${ }^{2}$ GET (CNRS/UPS/IRD), Toulouse, France \\ ${ }^{3}$ CNRM-GAME (CNRS and Météo-France), Toulouse, France \\ ${ }^{4}$ IRD, Hydrosciences, Montpellier, France \\ ${ }^{5}$ LTHE (UJF), Grenoble, France \\ ${ }^{6}$ CETE Ile de France, Trappes, France \\ ${ }^{7} \mathrm{CEH}$, Wallingford, UK
}

Correspondence to: F. Lohou (fabienne.lohou@aero.obs-mip.fr)

Received: 24 June 2013 - Published in Atmos. Chem. Phys. Discuss.: 10 July 2013

Revised: 6 March 2014 - Accepted: 12 March 2014 - Published: 17 April 2014

\begin{abstract}
This study analyses the response of the continental surface to rain events, taking advantage of the longterm near-surface measurements over different vegetation types at different latitudes, acquired during the African Monsoon Multidisciplinary Analysis (AMMA) by the AMMA$\mathrm{CATCH}$ observing system. The simulated surface response by nine land surface models involved in AMMA Land Model Intercomparison Project (ALMIP), is compared to the observations. The surface response, described via the evaporative fraction (EF), evolves in two steps: the immediate surface response (corresponding to an increase of EF occurring immediately after the rain) and the surface recovery (characterized by a decrease of EF over several days after the rain). It is shown that, for all the experimental sites, the immediate surface response is mainly dependent on the soil moisture content and the recovery period follows an exponential relationship whose rate is strongly dependent on the vegetation type (from 1 day over bare soil to 70 days over forest) and plant functional type (below and above 10 days for annual and perennial plants, respectively). The ALMIP model ensemble depicts a broad range of relationships between EF and soil moisture, with the worst results for the drier sites (high latitudes). The land surface models tend to simulate a realistic surface recovery for vegetated sites, but a slower and more variable EF decrease is simulated over bare soil than observed.
\end{abstract}

\section{Introduction}

The monsoon is the main source of precipitation over West Africa. It generates long-lived mesoscale systems which provide 80 to $90 \%$ of the annual rainfall in the Sahel (D'Amato and Lebel, 1998). Rainfall is characterized by high intermittency and large spatial variability, as well as high temporal variability at the synoptic, intraseasonal, interannual and multidecadal timescales (Lebel et al., 2009; Nicholson, 2013). Land-atmosphere exchanges and surface fluxes are impacted by rainfall variability at all scales, either as a direct response to soil water availability or through vegetation changes, and have been identified as major influences on climate and weather in West Africa (Eltahir and Gong, 1996; Zeng et al., 1999; Koster et al., 2004; Taylor et al., 2011b). Recent results demonstrated that convection triggering, which is a critical process in the tropics, was significantly enhanced by mesoscale heterogeneity of surface soil moisture (Taylor et al., 2011a, 2012). Antecedent rain strongly influences the spatial structure of surface fluxes, with high latent heat flux and low sensible heat flux over recently wetted surfaces.

The occurrence of these patterns of surface fluxes is driven primarily by spatial variability of rainfall and the size and life cycle of mesoscale convective system (MCS) and squall lines. However, it is also strongly related to the way the 
surface responds to a rain event, which is the focus of the present study. Immediately after a convective rain event, the partitioning of surface fluxes favours the latent heat flux. During the following days, the sensible heat flux progressively increases with the drying of the surface. The surface thus goes from relatively cold/moist to relatively warm/dry conditions over time, which in turn influences the boundary layer (Schwendike et al., 2010).

Evapotranspiration can be limited by several controls. Among them, soil moisture has been extensively documented (Koster et al., 2004; Seneviratne et al., 2006; Teuling et al., 2009; for a review see Seneviratne et al., 2010). The strongest control of evaporative fraction (EF) by soil moisture is found in the so-called transition regime. Soil moisture and EF are usually linearly related for soil moisture ranging from wilting point to a critical value (smaller than the field capacity). In the drier and wetter regimes, the control of EF by soil moisture becomes elusive. The linear relation in the transition regime, however, largely depends on other controls like plant and soil properties.

At the synoptic timescale (few days), the temporal dynamics of the evapotranspiration after a rain event have been studied in semi-arid regions by Kurc and Small (2004), who highlighted the marked differences between grassland and shrubland sites in New Mexico. Focusing on the end-of-season drying for 15 sites worldwide (including sites in Africa), Teuling et al. (2006) pointed out a large variability of drying dynamics, and suggested a prominent importance of vegetation rooting depth. These authors further proposed a possible link between rooting depth and aridity, leading to the observed slower decrease of latent heat flux in drier climates. Based on a comparison with data, Teuling et al. (2006) went on to highlight shortcomings in simulations of offline land surface models (LSMs) involved in the Global Soil Wetness Project 2. A large variability in the LSM response to rain events was also observed by Lohmann and Wood (2003) during the Red-Arkansas PILPS intercomparison exercise, although the absence of measurements prevented the pinpointing of model errors. Gash et al. (1997) used the HAPEXSahel experiment data set to characterize evapotranspiration over three land cover types in Southwest Niger. Although HAPEX-Sahel was a reference experiment devoted to surface energy balance measurements over the Sahel, most measurements only focused on the Niamey region, and over a relatively short time period. Altogether, these studies suggest that LSMs might have difficulties in representing flux dynamics in West Africa. Furthermore, when considering land surface behaviour at the regional scale, it is clear that distinct behaviour of different land cover types needs to be considered.

The AMMA (African Monsoon Multidisciplinary Analysis; Redelsperger et al., 2006) and the AMMA-CATCH observing system (Lebel et al., 2009) were designed to more fully document the multiscale monsoon system over West Africa, where surface stations are scarce and long-term mea- surements are lacking. Several sites were implemented along a south-north transect providing a rich long-term data set over different vegetation types and climates at different latitudes (Guyot et al., 2009; Ramier et al., 2009; Timouk et al., 2009; Lohou et al., 2010). In parallel, modelling of the land surface during the monsoon was addressed by the AMMA Land Surface Model Intercomparison Project (ALMIP) (Boone et al., 2009). The ALMIP phase 1 scientific objective was to separate the coupling between atmosphere and land surface from the many other couplings (atmospheric, biological) which drive the monsoon system, in order to evaluate LSM sensitivity to atmospheric forcings and intrinsic physics, and to develop a climatology of surface diagnostics (Boone et al., 2009). The multimodel offline intercomparison used diagnostics from nine LSMs. Even with the same atmospheric forcings, the simulated annual cycle shows a high variability of soil water storage from LSM to LSM (Grippa et al., 2011). This variability partly originates in the accumulation with time of differences occurring during and after each rain event of the monsoon season. Guichard et al. (2010) illustrated the development of such differences in modelled surface fluxes after the occurrence of a large MCS.

Our objectives here are to characterize the dynamics of the evaporative fraction after a rain event at the temporal scale of a few days. As noted above, this timescale is important for convective triggering and boundary layer dynamics in the Sahel. This also requires consideration of the seasonal timescale, as root zone soil moisture and vegetation growth are likely to modulate high-frequency EF dynamics. Performed over a variety of land cover types and climate zones along a $\mathrm{S}-\mathrm{N}$ transect in West Africa using observations, this study investigates the sensitivity of EF dynamics to surface characteristics, comparing bare soil with annual and perennial vegetation types, alongside site latitude and soil type. Whereas previous studies (Hunt et al., 2002; Kurc and Small, 2004; Teuling et al., 2006) focused on the period after rain during which the EF decreases, this study also considers the immediate surface response by comparing the surface fluxes before and after the rain. In the context of the African monsoon, this seasonally evolving fast flux response to rain is important as it strongly influences the boundary layer and its ability to support deep convection on consecutive days (Schwendike et al., 2010). Finally, a range of LSMs are examined to test their representation of these dynamics, and to identify possible weaknesses.

The AMMA experimental surface database and the ALMIP LSM simulations are introduced in Sect. 2. The same methodology is applied both for rain event selection and surface response characterization (Sect. 3). The observed EF dynamics are analysed as a function of soil moisture and vegetation type (Sect. 4.1). The same analysis is carried out with the ALMIP models and the simulated surface response is compared to the observed one (Sect. 4.2). Finally, the results are discussed (Sect. 5) and conclusions drawn (Sect. 6). 


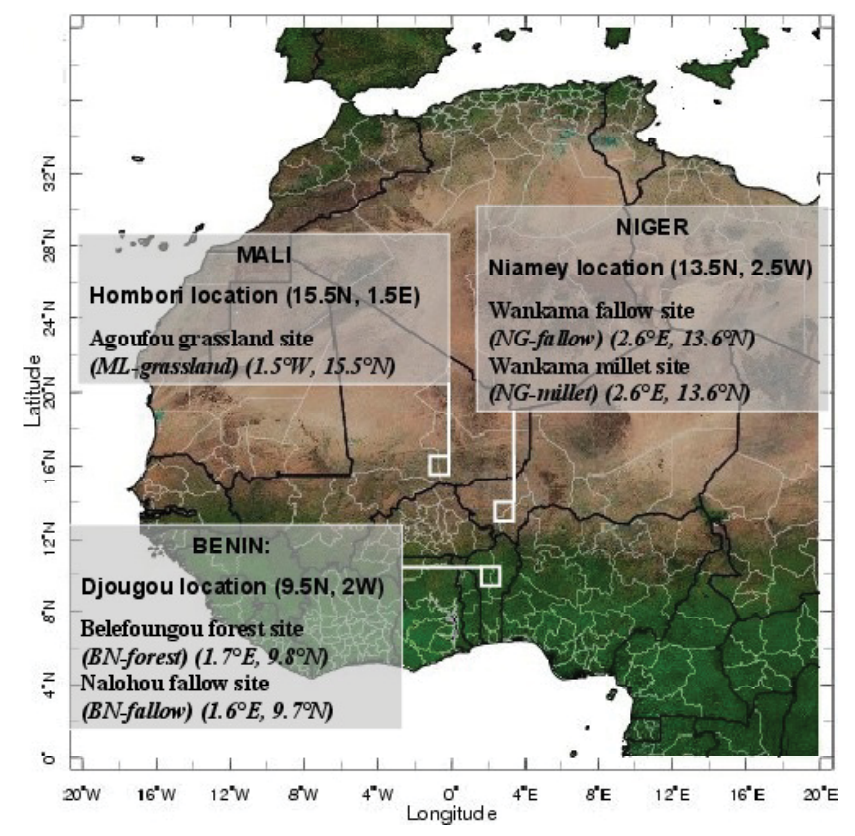

Fig. 1. Djougou (Benin), Niamey (Niger) and Hombori (Mali) grid cells containing experimental sites, where LSM data have been extracted.

\section{Data and simulations}

Observations from AMMA provide for the first time a continuous multi-year data set which characterizes land-surface exchanges and surface properties in West Africa. Several experimental surface sites were deployed along a meridional transect crossing Benin, Niger and Mali and characterizing different climatic regimes from humid tropical to sub-Saharan regimes. Five of these experimental sites provided all the necessary data (surface state and land-atmosphere exchange characteristics) for this study over several seasonal cycles (Fig. 1): forest and fallow in Benin, fallow and millet in Niger and grassland in Mali (hereafter BN-forest, BN-fallow, NGfallow, NG-millet and ML-grassland, respectively). In addition to the measurements, simulations from nine LSMs involved in ALMIP where extracted at three locations (hereafter Djougou, Niamey and Hombori) encompassing the experimental sites (Fig. 1).

\subsection{Flux station sites}

The two Benin sites are located in the Donga catchment which is characterized by a typical Sudanian climate. Rainfall is $1200 \mathrm{~mm} \mathrm{yr}^{-1}$ on average, and potential evapotranspiration is around $1500 \mathrm{~mm} \mathrm{yr}^{-1}$. During the monsoon season, from June to October, rainfall events are regular with short dry periods between them $(\sim 3$ days). Before and after the core rainy season (July to September), sparse rainfall occurs during the long transition period from March to May and in November. The climate is well-suited for extensive agricul- tural practice (30\% of the area) but large areas are still covered with shrub savannah $(60 \%)$. Only $10 \%$ of the surface is occupied by forest. Down to $0.5 \mathrm{~m}$ depth, the soil is composed of sand and loam. Deeper soil also contains clay that holds water for vegetation. The first flux tower is located on a fallow site surrounded by various crops (Nalohou: $1.6^{\circ} \mathrm{E}$, $9.7^{\circ} \mathrm{N}, 449 \mathrm{~m}$ ). The second is set up over a forest site (Bellefoungou: $1.7^{\circ} \mathrm{E}, 9.8^{\circ} \mathrm{N}, 414 \mathrm{~m}$ ) where trees are $14 \mathrm{~m}$ high on average. These two flux stations are representative of the vegetation density range of this area.

The two Niger sites are located in the Wankama catchment $\left(2.6^{\circ} \mathrm{E}, 13.6^{\circ} \mathrm{N}\right)$, typical of the cultivated Sahelian environment of Southwest Niger (Cappelaere et al., 2009). The climate is semi-arid tropical with a mean annual rainfall of about $510 \mathrm{~mm}$ and a potential evapotranspiration of around $2500 \mathrm{~mm} \mathrm{yr}^{-1}$ (Favreau et al., 2009). Ninety percent of the rainfall occurs from June to September, mostly from mesoscale convective systems. Soils consist of weakly structured sands and are prone to surface crusting and erosion. The former natural woody savannah has now been largely turned into a mosaic of rain-fed millet fields and shrubcovered fallow patches (dominated by Guiera senegalensis). The two observation sites sample these two dominant land cover types.

The Mali site is located in the Gourma area, south of the Niger river $\left(1.5^{\circ} \mathrm{W}, 15.5^{\circ} \mathrm{N}\right)$. The site is typical of pastoral Sahel, where cropland is scarce (less than $4 \%$ for the Gourma super-site Mougin et al., 2009). Annual precipitation averages $350 \mathrm{~mm}$ and falls between July and mid-September (Frappart et al., 2009). Three main landscape units dominate. The main landscape unit consists of large sandy dunes, with deep soils, covered by annual grasses and scattered trees, which occupy $60 \%$ of the area. Very shallow soils, either rocky outcrops (sandstones, schists) or iron pans, with very scarce trees, are second in terms of surface, occupying $35 \%$ of the area. Seasonally flooded valleys and ponds, usually densely vegetated, make up the rest of the landscape (5\%). The Agoufou flux tower is set up on a sandy dune, which is the dominant ecosystem (Timouk et al., 2009).

The surface and atmospheric properties analysed in this study are listed in Table 1. High-frequency measurements were processed with the EdiRe software (Version 1.4.3.1167, R. Clement, University of Edinburgh) on $30 \mathrm{~min}$ sample to compute sensible and latent heat flux. CarboEurope recommendations (Mauder and Foken, 2004) were used, including despiking, double rotation, cross-correlation for the derivation of the time lag between the sonic anemometer and the gas analyser, and spectral and Webb corrections. The soil moisture was measured at different depths at each site (Table 1). It has been vertically integrated over the first metre to ease the comparison between sites and with the LSMs. Soil moisture and rainfall are half-hourly averaged to match the resolution of the surface fluxes.

In order to highlight the seasonal cycle, the evolution of the weekly rainfall, and the weekly averaged leaf area index 
Table 1. Variables and associated instrument used at the experimental sites.

\begin{tabular}{|c|c|c|}
\hline Variable & Instrument & Reference \\
\hline Rainfall & $\begin{array}{l}0.5 \mathrm{~mm} \text { resolution tipping } \\
\text { bucket rain gauge }\end{array}$ & Frappart et al. (2009) \\
\hline $\begin{array}{l}\text { Leaf area } \\
\text { index }\end{array}$ & $\begin{array}{l}\text { Photographs analysed } \\
\text { with CAN-EYE software } \\
\text { Leaves collection along a } 1 \mathrm{~km} \text { transect }\end{array}$ & $\begin{array}{l}\text { Boulain et al. (2009) } \\
\text { Mougin et al. (2009) }\end{array}$ \\
\hline Soil moisture & $\begin{array}{l}\text { CS616 capacity probes (Campbell Sci. Inc.) } \\
\text { at } 0.05,0.1,0.2,0.4,0.6 \text { and } 1 \mathrm{~m} \text { depths at Benin sites } \\
\text { at } 0.1,0.5 \text { and } 1.0 \mathrm{~m} \text { depths at Niger sites } \\
\text { at } 0.05,0.1,0.4,1.2,2.2 \mathrm{~m} \text { depths at Mali site }\end{array}$ & $\begin{array}{l}\text { Ramier et al. (2009) } \\
\text { de Rosnay et al. (2009) }\end{array}$ \\
\hline $\begin{array}{l}\text { Sensible } \\
\text { and } \\
\text { latent } \\
\text { heat flux }\end{array}$ & $\begin{array}{l}\text { Cstat-3 } 20 \mathrm{~Hz} \text { sonic anemometer (Campbell Sci. Inc) } \\
\text { and Li7500 infrared gas at } 5 \text { (BN-fallow), } 18 \text { (BN-forest), } \\
5 \mathrm{~m} \text { (NG-fallow and NG-millet) } \\
\text { and } 3.5 \mathrm{~m} \text { (ML-grassland) heights }\end{array}$ & $\begin{array}{l}\text { Ramier et al. (2009) } \\
\text { Timouk et al. (2009) }\end{array}$ \\
\hline Radiation flux & Kipp \& Zonen CNR1 Radiometer & Timouk et al. (2009) \\
\hline
\end{tabular}

(LAI), EF and its standard deviation and soil water content at each site are presented in Fig. 2. Weekly averages are used to make the figure easier to interpret. The EF is computed as

$\mathrm{EF}=\mathrm{LE} /(\mathrm{LE}+H)$,

where LE and $H$ represent the weekly averaged latent and sensible heat flux, respectively. The measurements were acquired over different periods at each site, between June 2006 and December 2009. There is a good availability and continuity of the measurements with the exception, in 2009, of the LAI at the Benin sites. These data show the expected southnorth gradient of the rainfall and the soil water content. The seasonal evolution of EF is clearly tied to the duration of the monsoon season, with EF reaching similar high values (0.70.8 ) at the different sites, for typically 4 months in Benin (June to September), 3 months in Niger (July to September) and 2 months in Mali (July and August).

\subsection{Land Surface Model Intercomparison Project}

The nine LSMs used in this study and their ALMIP configuration are summarized in Table 2. In ALMIP phase 1, regional-scale forcing is used. The land surface characteristics for vegetation and soil texture from the ECOCLIMAP database (Masson et al., 2003) were used by all models except HTESSEL and SSiB. The surface meteorology is based on the European Centre for Medium-Range Weather Forecast (ECMWF) short-term forecast data and consists of 3hourly temperature, specific humidity and wind components at $10 \mathrm{~m}$, as well as surface pressure. For the ALMIP experiment 3 used in this study, the precipitation is from the Tropical Rainfall Measurement Mission (TRMM) precipitation product 3B-42 (Huffman et al., 2007) and the incoming long-wave and short-wave fluxes are provided by the LANDSAF project (Boone et al., 2009). It is important to note that the differences between the simulations shown hereafter can be directly linked to distinct formulations and/or configuration (and surface classification parameters for HTESSEL and $\mathrm{SSiB}$ ) of the LSMs as they all share the same forcing.

The LSM simulations cover the period 2002 to 2007 with a $0.5^{\circ}$ spatial resolution and a $3 \mathrm{~h}$ time step. The simulated sensible and latent heat fluxes are used to compute the EF in the same way as done with the measurements (Eq. 1). The simulated transpiration (TR) allows an estimation of the vegetation activity. A threshold of 0.1 for transpiration to evapotranspiration ratio (TR/ET) will be used to distinguish sites dominated by bare soil versus soil with vegetation canopy. The time change of the vertically integrated soil moisture, $\Delta S$, is one of the available variables for soil moisture. $S$ is preferable to a soil moisture-based index since it results from the soil water budget including the precipitation forcing $P$, the evapotranspiration ET and the total runoff $R$ :

$\frac{\partial S}{\partial t}=P-\mathrm{ET}-R$

A time integration of $\Delta S$, simulated with a $3 \mathrm{~h}$ time step, defines what will be called hereafter the soil water content anomaly (SWCA) relative to 1 January 2002. The SWCA range of variation can be compared from model to model, and to the range of variation of the measured soil moisture. The evolution of the weekly averaged SWCA, EF and its standard deviation simulated by the nine LSMs at the three locations are illustrated in Fig. 3 for the period 2006-2007. The overlap of simulated and measured data in 2007 allows a direct comparison of the seasonal cycle of EF in Fig. 4.

Broadly speaking, EF seasonal evolutions at the three latitudes are well represented by the LSMs: the higher the latitude, the shorter the period with high EF (4 months in Djougou, 3 months in Niamey and 2 months in Hombori) 
(a)

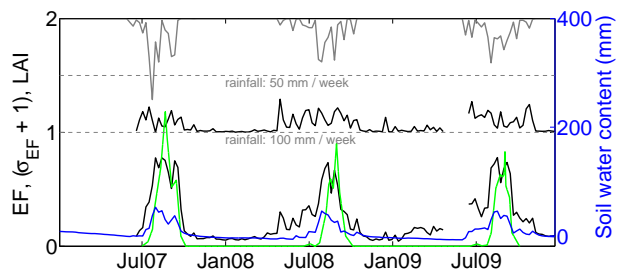

(b)

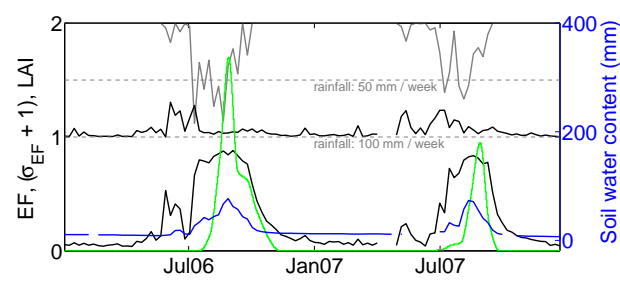

(d)

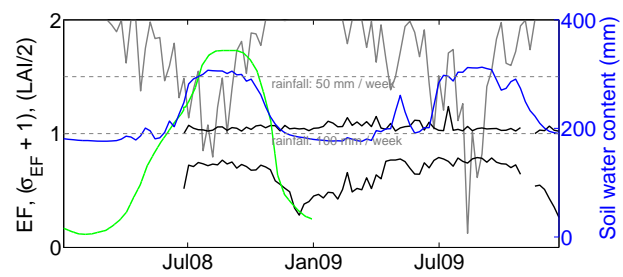

(c)

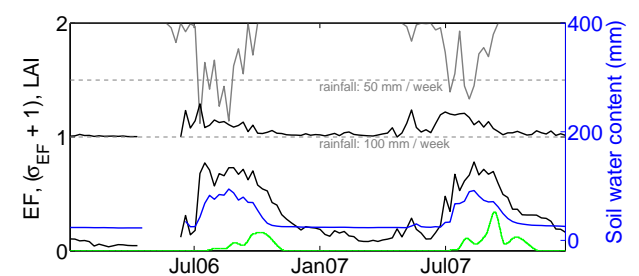

(e)

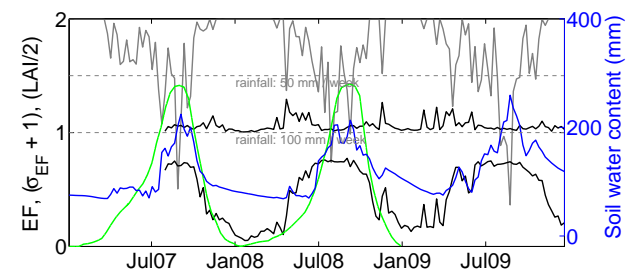

Fig. 2. Weekly (black) $\mathrm{EF}$ and its standard deviation ( $\sigma_{\mathrm{EF}}-$ to avoid superposed curves, $\sigma_{\mathrm{EF}}+1$ is plotted), (green) leaf area index (LAI) (LAI / 2 is plotted for Benin sites), (blue) soil water content and (grey) weekly rainfall (with an inverted $y$ axis) measured at (a) ML-grassland, (b) NG-fallow, (c) NG-millet, (d) BN-forest, (e) BN-fallow.

(Fig. 4). However, weekly averaged EF discrepancies between the LSMs can reach $+60 \%$ during the rainy season, and the surface drying at the end of the rainy season is simulated quite differently by the LSMs. SWCA discrepancies between the LSMs are also important with a relative difference of $+100 \%$ or more (Fig. 3). It would be tempting to link EF and SWCA variability, but the depth of the simulated soil layer varies among LSMs, differences in intercepted water can be important, the water storage in the deep soil is treated differently and runoff varies among LSMs. Therefore, differences in SWCA do not explain differences in EF in a simple way, as already pointed out by Desborough et al. (1996) who compared 13 LSM simulations of bare soil evaporation.

Although it is not straightforward to compare local measurements to a larger-scale simulated pixel, one can remark that ALMIP models simulate a much larger soil water content variation than is observed. Soil water content at both BN-fallow and BN-forest (Fig. 2) has a $100 \mathrm{~mm}$ variation between dry and wet conditions, whereas LSMs give at least a 200 to $300 \mathrm{~mm}$ variation (Fig. 3). The same features can be observed at the Niger and Mali sites where a 50 to $70 \mathrm{~mm}$ variation of soil moisture is measured and a 100 to $150 \mathrm{~mm}$ variation is simulated. Such a difference is likely, in part, explained by the deeper soil layer simulated by the LSM than the $1 \mathrm{~m}$ depth layer considered for the observations to es- timate the vertically integrated soil moisture. In Mali and Niger, the soil moisture seasonal variation of the layer between 1 and $1.5 \mathrm{~m}$ depth varies from 20 to $40 \mathrm{~mm}$ depending on the site and year (not shown); unfortunately, soil moisture measurements below $1 \mathrm{~m}$ are not available at all sites and with a sufficient temporal coverage.

The standard deviation of EF at the weekly timescale (Figs. 2 and 3) gives an indication of the effect of the rain events on the land surface: the larger the EF standard deviation, the higher the effect of the rain events. High standard deviations of about 0.4 (50\% of EF value) can be observed at all sites at the beginning of the monsoon. This impact decreases progressively throughout the rainy season in Benin, lasts longer in Niger, and stays high during the whole monsoon in Mali. Whilst this general trend of the standard deviation is well depicted at each latitude by the LSMs, the value is larger than observed (between 0.6 and 0.8 in the early monsoon season). Analysis is now conducted by looking at the evolution of the surface fluxes for days either side of a rain event. 
Table 2. LSM participating in ALMIP experiment 3. The model configuration used for ALMIP is summarized in the last column with the number of vertical soil layers (L), number of energy budgets E per tile, and the soil-vegetation parameters used (SV). Tile refers to the maximum number of completely independent land surface types permitted within each grid box.

\begin{tabular}{lll}
\hline Model acronym & $\begin{array}{l}\text { Institute } \\
\text { Recent reference }\end{array}$ & ALMIP configuration \\
& ECMWF, UK & 4L, 6 tiles, 1E \\
HTESSEL & Balsamo et al. (2009) & SV: ECMWF \\
& IPSL, France & 11L, 13 tiles, 1E \\
ORCHIDEE_CWRR & D’Orgeval et al. (2008) & SV: ECOCLIMAP \\
& CNRM, France & 5L, 1 tile, 1E \\
ISBA_DF & Boone et al. (2000) & SV: ECOCLIMAP \\
& CEH, UK & 4L, 9 tiles, 1E \\
JULES & Essery et al. (2003) & SV: ECOCLIMAP \\
& CETP, France & 2L, 12 tiles, 2E \\
SETHYS & Saux-Picart et al. (2009) & SV: ECOCLIMAP \\
& CETP/LSCE(NCEP) & 7L, 12 tiles, 1E \\
NOAH & Decharme (2007) & SV: ECOCLIMAP \\
& UPMC, France & 3L, 5 tiles, 1E \\
CLSM & Koster et al. (2000) & SV: ECOCLIMAP \\
& LETG, France & 3L, 1 tile, 2E \\
SSiB & Xue et al. (1991) & SV: SSiB \\
& IWP, Russia & 3L, 1 tile, 1E \\
SWAP & Gusev et al. (2006) & SV: ECOCLIMAP \\
& & \\
\hline
\end{tabular}

\section{Methods}

A common method for selecting rain events and quantifying the associated surface flux response is applied to both measured and simulated data.

\subsection{Rain event selection}

The criteria defined to detect and select a rain event are as follows:

- The rainfall must be preceded by $24 \mathrm{~h}$ without rain, and this period is used to estimate the initial state of the surface.

- The rainfall must be followed by at least $24 \mathrm{~h}$ without rain to analyse the surface response. The longer the period without rain, the longer the surface recovers from the rain event.

- Only events with cumulated rainfall above $3 \mathrm{~mm}$ are selected.

- When two consecutive rainfall events are separated by less than $3 \mathrm{~h}$, they are considered as the same rain event.

According to these criteria, 34 locally observed events are selected at BN-forest (2008-2009), 50 at BN-fallow (20072009), 28 for Niger (2006-2007), and 48 for Mali (20072009). The selected ALMIP rain events at each location are the same for all LSMs since they are driven by the same atmospheric forcings. In 6 years, 78, 96 and 88 rain events were selected at Djougou, Niamey and Hombori locations, respectively. The rain events in the simulated and measured data sets might not be the same since TRMM rainfall does not always coincide with local measurements, but the statistical analysis of long-term data sets allows a comparison between observed and simulated mean surface responses.

\subsection{Surface response}

The surface state is considered from the turbulent flux partitioning point of view, via the EF. This limits the impact of temporal variability of net radiation on our calculations. $H$ and LE are averaged to get the mean surface response over a $24 \mathrm{~h}$ period of time. Only measurements between 06:00 and 18:00 UTC are used to get $H$ and LE means from which EF is computed. Several experimental studies show that EF can be considered, under stable radiation and low to moderate advection, as a constant during daytime hours - referred to as the self-preservation of EF (Crago and Qualls, 2013). Day $D 0$ is defined as the $24 \mathrm{~h}$ preceding the rainfall, and day $D n$ $(n \geq 1)$ covers the period from $(n-1) \times 24$ to $n \times 24 \mathrm{~h}$ following the end of the rainfall. As an example, for a rain event finishing at 15:00 UTC on the 22 July, the EF at $D 1$ is the mean EF on the 22 July between 15:30 and 18:00 UTC and on the 23 July between 06:00 UTC and 15:00 UTC.

Figure 5 shows an example of the evolution of EF before $(D 0)$ and after ( $D 1$ to $D 5)$ a rain event at NG-fallow. EF on $D 0$ gives the initial surface flux partitioning. The rain leads to an increase of $\mathrm{EF}$ on $D 1$. The ratio $\mathrm{EF}(D 1) / \mathrm{EF}(D 0)$ depicts the immediate response of the surface. The period following 
(a)

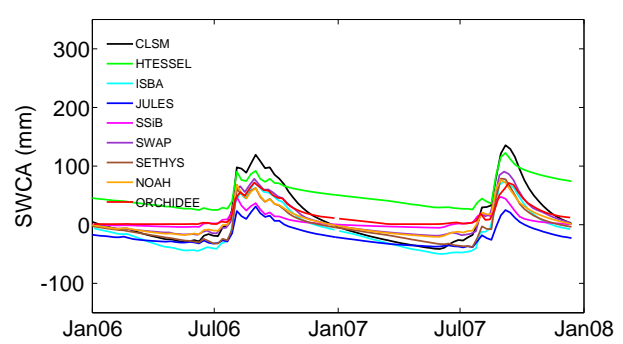

(c)

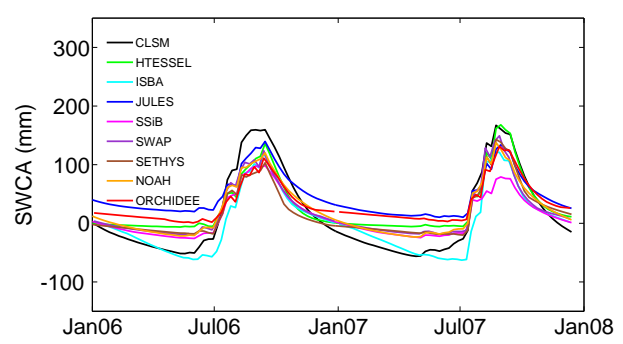

(e)

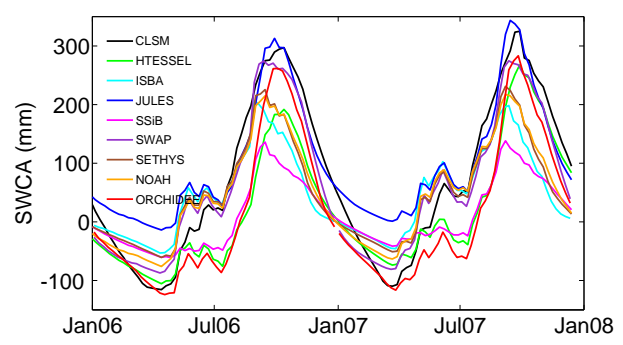

(b)

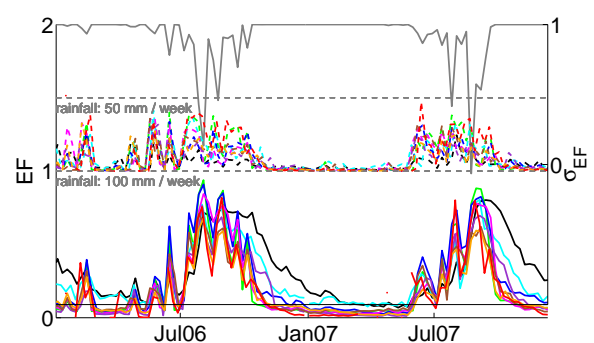

(d)

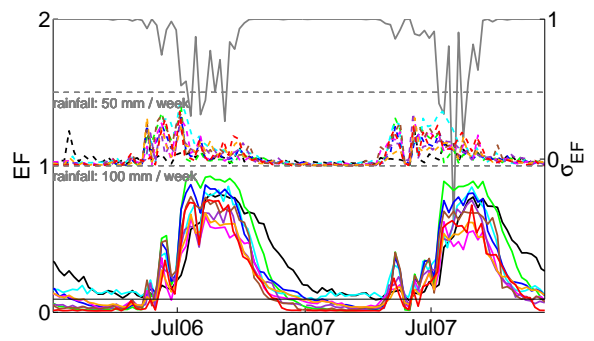

(f)

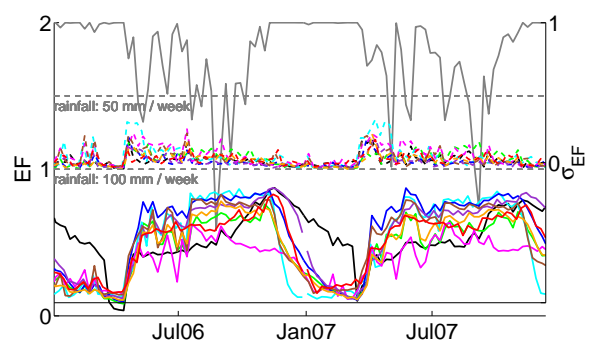

Fig. 3. Weekly (left panels) SWCA and (right panels, continuous coloured lines) EF and (dashed coloured lines) its standard deviation ( $\left.\sigma_{\mathrm{EF}}\right)$ from January 2006 to December 2007 at (a, b) Hombori, (c, d) Niamey and (e, f) Djougou locations. Colours stand for the nine LSMs. Weekly rain amount (grey, with in inverted $y$ axis), which is one of the atmospheric forcings, is overplotted on the right panels.

$D 1$, during which EF tends to decrease with time, is the drying period during which the surface recovers from the rain event.

In order to model the surface recovery, Wallace and Holwill (1997) applied a two-stage model on HAPEX-Sahel measurements. Evaporation is assumed to occur at its potential rate for 1 day after the rain, then in a second phase, decreases as the square root of time. The surface recovery has also been modelled with a time-dependent exponential relationship for (1) EF decrease after the rain over tussock and rye grasslands in New Zealand by Hunt et al. (2002) and (2) LE (and LE normalized by net radiation and global radiation) decrease over various vegetation types by Teuling et al. (2006). The EF expression reads as

$\mathrm{EF}(D)=\mathrm{EF}(D 1) \exp \left(-D / \tau_{1}\right)$

where $D$ is time in days after the rainfall and $\tau_{1}$ is the best fit exponential constant. This model describes the EF decrease from the day after the rainfall $(\operatorname{EF}(D 1))$ until the zero value of EF. Kurc and Small (2004) used a similar method to model soil moisture, evapotranspiration and EF over grass and shrub in central New Mexico. The EF expression is then

$\mathrm{EF}(D)=(\mathrm{EF}(D 1)-\mathrm{EF}(D n)) \exp \left(-D / \tau_{2}\right)+\mathrm{EF}(D n)$,

where the exponential constant $\tau_{2}$ is the best fit along an $n$ day-long drying period which does not necessarily extend to a complete drying of the soil (as is the case in Eq. 3).

The use of both exponential constants appears to be complementary - the former integrates all the timescales of the successive processes involved in the decrease of EF down to zero, the second gives the timescale of the processes which dominate in the surface drying during the $D 1$ to $D n$ period. In this study, $\tau_{1}$ and $\tau_{2}$ are defined as the inverse of the slope of the linear regression of $\ln (\mathrm{EF}(D) / \mathrm{EF}(D 1))$ and $\ln ((\mathrm{EF}(D)$ - $\mathrm{EF}(D n)) /(\mathrm{EF}(D 1)-\mathrm{EF}(D n)))$ with time, respectively. $\tau_{1}$ and $\tau_{2}$ are determined for the median surface response computed over the selected rain events whose recovery periods are at least 5 days long. The 5-day recovery period is a compromise between the longest possible period to correctly 
(a)

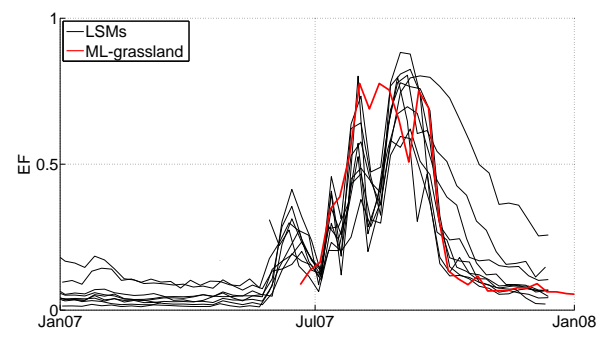

(c)

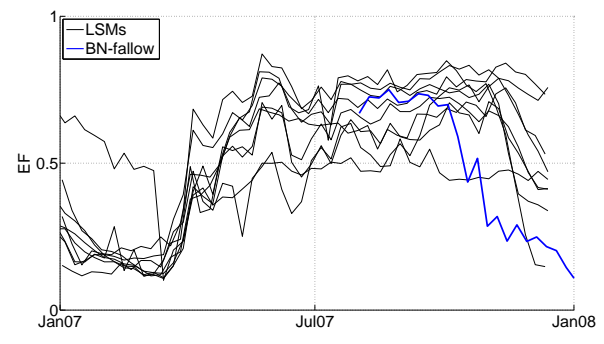

(b)

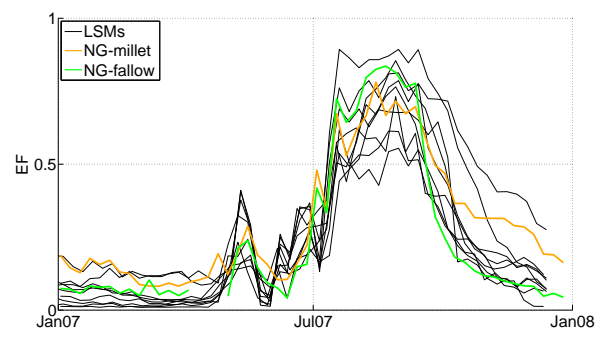

Fig. 4. Weekly EF from January 2007 to December 2007 (grey lines) simulated at (a) Hombori, (b) Niamey and (c) Djougou and (coloured lines) observed at (a) ML-grassland, (b) NG-millet and NG-fallow, and (c) BN-fallow.

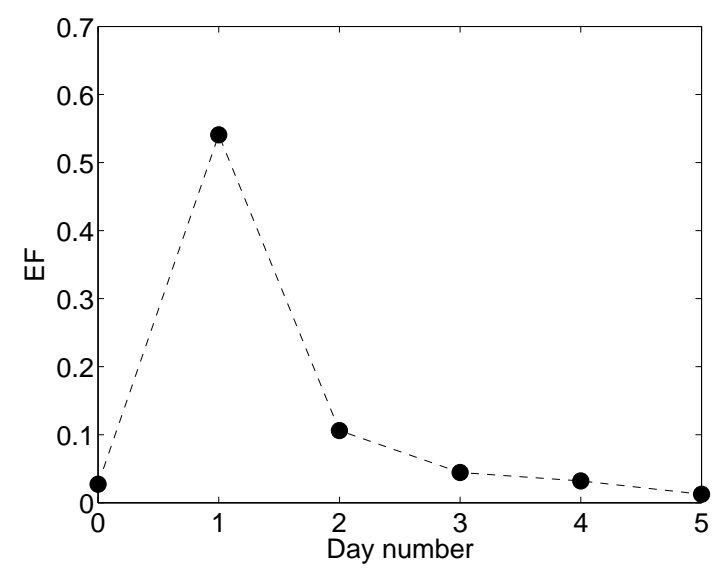

Fig. 5. Example of mean EF evolution before $(D 0)$ and after ( $D 1$ to $D 5)$ a rainfall which occurred at NG-fallow at the beginning of the monsoon.

represent the surface evolution throughout its drying, and the highest number of rain events used to compute the median surface response. Uncertainties in $\tau_{1}$ and $\tau_{2}$ are provided by the uncertainty values from the linear regression.

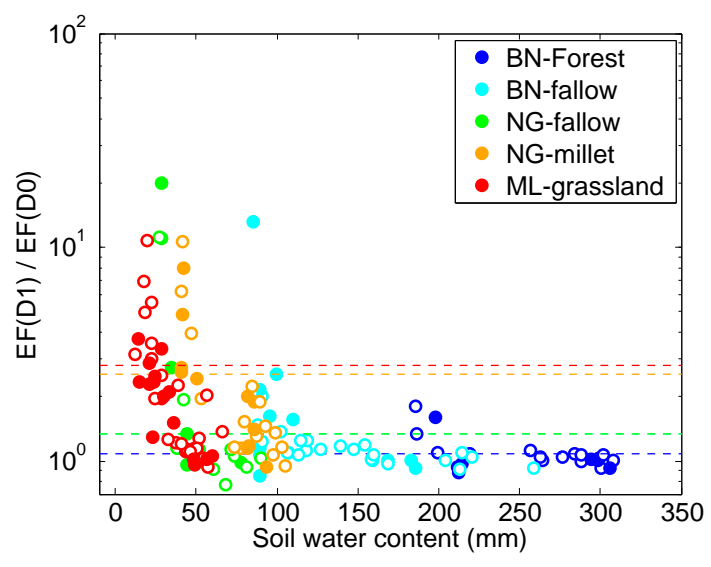

Fig. 6. Immediate surface response $(\mathrm{EF}(D 1) / \mathrm{EF}(D 0))$ against vertically integrated soil water content at $D 0$. Horizontal dashed lines indicate the $\mathrm{EF}(D 1) / \mathrm{EF}(D 0)$ upper quartile. Colours stand for the different sites; open and full circles are respectively for cumulated rainfall $\leq 8 \mathrm{~mm}$ and $>8 \mathrm{~mm}$.

\section{Results}

\subsection{Observed surface response to a rain event}

\subsubsection{Immediate surface response}

Several surface and atmospheric properties can drive the amplitude of the immediate surface response $(\mathrm{EF}(D 1) / \mathrm{EF}(D 0))$ : soil water content, vegetation and its root layer depth, rainfall, potential evapotranspiration. Among them, the soil water content, because of its strong 
seasonal variation, is expected to dominate the evolution of $\mathrm{EF}(D 1) / \mathrm{EF}(D 0)$ throughout the monsoon. Actually, before the core of the rainy season, the surface soil water content is close to its annual minimum value, so that the first rainfall events change significantly the surface humidity and then lead to a strong increase of the EF (water limited regime). In contrast, the EF of a soil whose surface water content is already close to its field capacity value should not vary a lot after a rain event. These cases are very frequent in Benin (energy limited regime) but much less so in Mali, even at the end of the rainy season, as shown by EF standard deviation in Fig. 2.

The sensitivity of the immediate surface response to soil water content before the rain is shown in Fig. 6. Soil moisture varies across the sites according to (1) the latitude, (2) the soil texture and (3) the vegetation type. The extreme values are measured for the BN-forest (200 to $300 \mathrm{~mm}$ ) and for the MLgrassland (0 to $60 \mathrm{~mm}$ ). This shift aside, a similar behaviour is found for all the sites: the lower the soil water content, the higher the immediate surface response. These high immediate surface responses mainly occur at the beginning of the monsoon when the LAI is close to zero (not shown), when the vegetation activity is still very low (except for BN-forest site where the vegetation is almost evergreen). Consequently these high immediate responses are much more related to soil evaporation than transpiration.

Figure 6 suggests that there is no obvious distinction in surface flux response between smaller and larger rain event totals, based on an arbitrary threshold of $8 \mathrm{~mm}$. Lastly, no clear relationship was found between the potential evapotranspiration and the immediate response (not shown), meaning that atmospheric demand is never limiting evapotranspiration on these time scales for these sites.

\subsubsection{Surface recovery}

Similar to the immediate surface response amplitude, the surface recovery amplitude is also expected to have a seasonal cycle. Figure 7 illustrates the strong link between the immediate surface response $(\mathrm{EF}(D 1) / \mathrm{EF}(D 0))$ and surface recovery amplitude on $D 2(\mathrm{EF}(D 1) / \mathrm{EF}(D 2))$. This relationship between the fluxes on days 1 and 2 after rain is consistent throughout the season, whatever the site. During the early monsoon, the EF increase on $D 1$ is mainly due to bare soil and interception evaporation, which weakens on $D 2$, implying a decrease of EF. Later in the season, both surface response and surface recovery amplitudes tend toward one when soil moisture is less affected by the rain and/or transpiration dominates evaporation. Besides this seasonal relationship, the dispersion of points about the dashed line is likely due to different factors (e.g. atmospheric demand, water interception, drainage).

Figure 8 combines EF evolution with time for all the rainfall events selected at each site. $\mathrm{EF}$ is normalized by $\operatorname{EF}(D 1)$ for more clarity. The rain events are further sorted into two

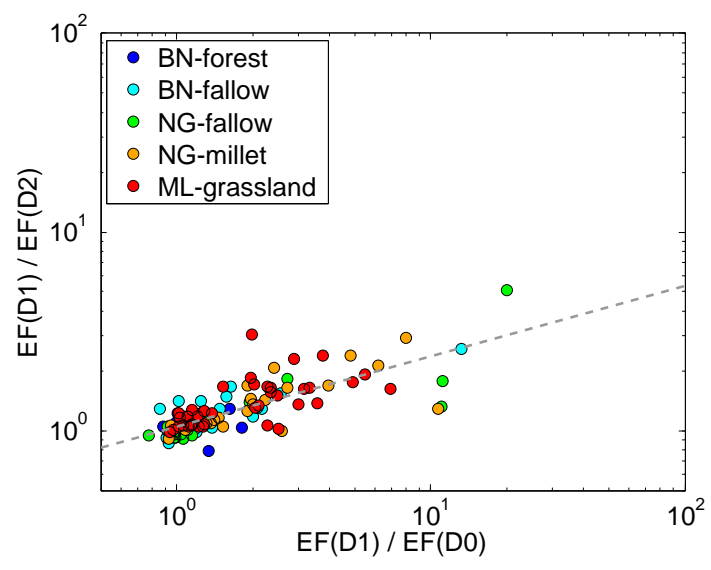

Fig. 7. Immediate surface response $(\mathrm{EF}(D 1) / \mathrm{EF}(D 0))$ against surface recovery on $D 2(\mathrm{EF}(D 1) / \mathrm{EF}(D 2))$. Colours stand for the different sites.

categories: rain events occurring on bare soil ( $\mathrm{LAI} \leq 0.01)$, and rain events occurring on soil with a vegetation canopy (LAI > 0.01). The low value of the LAI threshold used in this study permits the discrimination between totally bare soil and partially to densely vegetated surfaces. Sensitivity tests performed on this LAI threshold indicate only minor differences in averaged EF dynamic on bare soil and vegetated surface (not shown).

EF median evolution with time is computed up to $D 5$ for the vegetation and bare soil cases, using only rain events whose following dry period lasts at least 5 days. Values of $\tau_{1}$ and $\tau_{2}$ and their uncertainties are presented in Table 3 .

For bare soil, both $\tau_{1}$ and $\tau_{2}$ have low values: $\tau_{1} \sim 1.3$ 2.9 days and $\tau_{2} \sim 1$ day. For vegetation canopies, $\tau_{1}$ and $\tau_{2}$ are larger than for bare soil because the transpiration process is added to the evaporation and slows the decrease of EF. Dugas et al. (1996) observed qualitatively similar differences over arid surfaces in the southwestern United States. $\tau_{2}$ ranges from 1.7 to 5.5 days and can be compared to a value of 2 days found by Kurc and Small (2004). Values for $\tau_{1}$ for vegetation canopies are above 6 days, consistent with Hunt et al. (2002). Though the rooting depth is not the only control of transpiration, one can notice that the deeper the roots, the longer $\tau_{1}$, with 7 to 10 days for annual vegetation (MLgrassland and NG-millet, Fig. 8a and c), 10 to 21 days for fallow with shrubs (NG-fallow and BN-fallow, Fig. $8 \mathrm{~b}$ and e), and 74 days for the forest (BN-forest, Fig. 8d). As mentioned by Teuling et al. (2006), $\tau$ seems to have a stronger sensitivity to vegetation type than to soil type.

Uncertainties are generally lower than $10 \%$, except for NG-fallow where it is about $20 \%$, and for BN-forest where it reaches about $75 \%$. The latter can be explained by the availability of only two rain events with 5-day long recovery periods, and also because the recovery period is too short for this type of vegetation cover. However, $\tau_{1}$ of 74 days is consistent with values found by Teuling et al. (2006) for forest sites. 
(a)

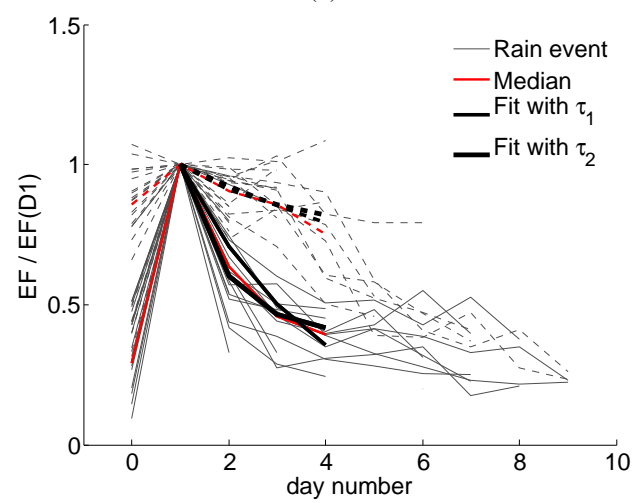

(b)

(c)

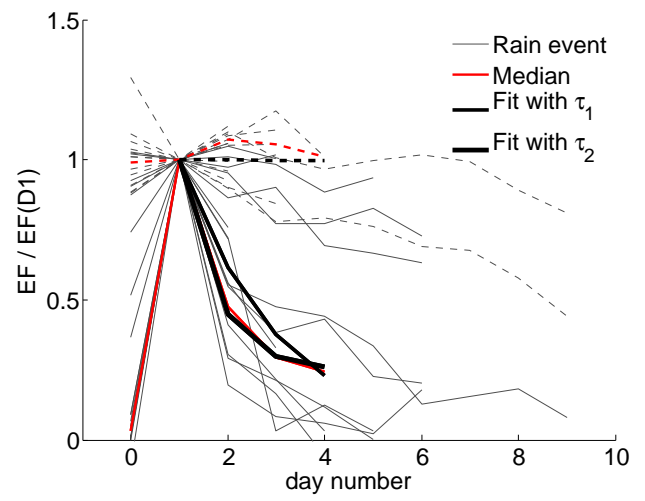

(d)

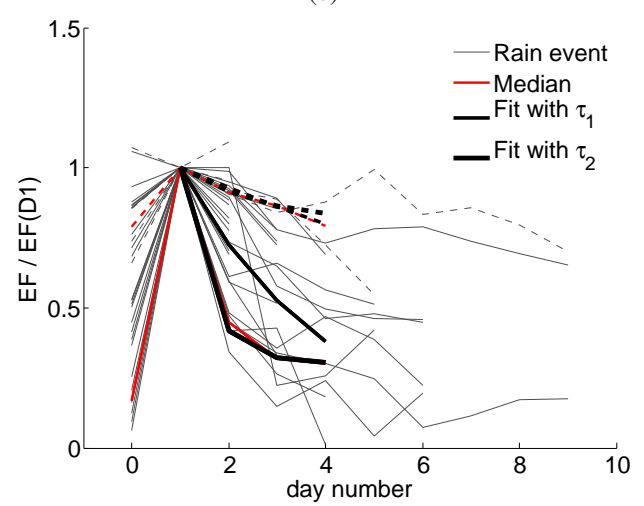

(e)
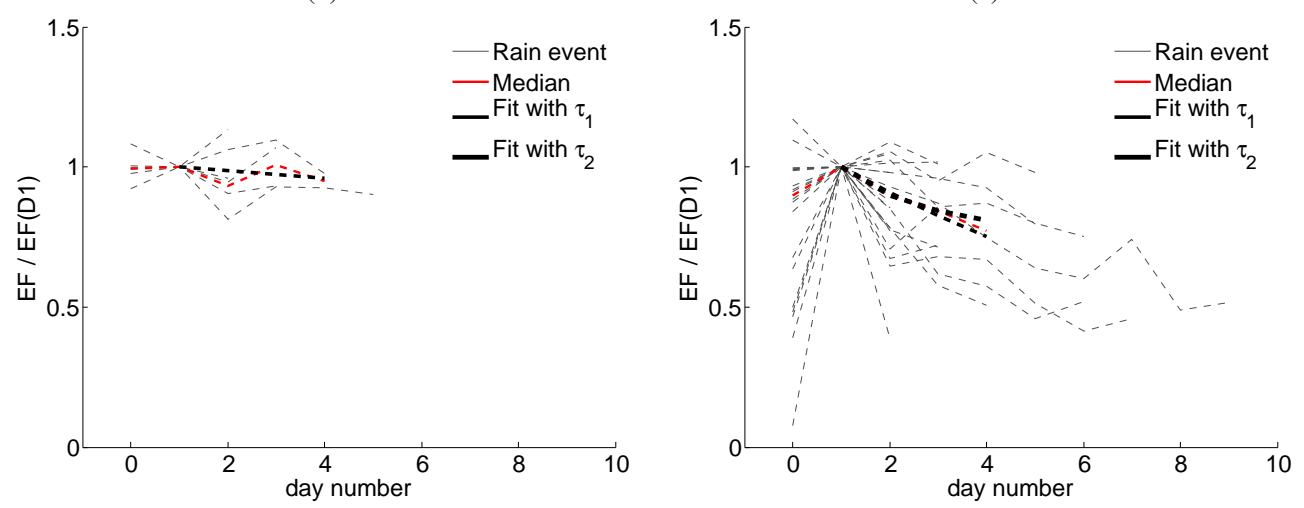

Fig. 8. Evolution of the daily normalized $\mathrm{EF}(\mathrm{EF} / \mathrm{EF}(D 1))$ before and after rain event for (a) ML-grassland, (b) NG-fallow, (c) NG-millet, (d) BN-forest (e) BN-fallow. Thin grey and red lines represent individual rain events and their median, respectively. Thin and bold dark lines represent the exponential fit with $\tau_{1}$ and $\tau_{2}$, respectively. The rain events are sorted in two categories: (continuous line) rain events occurring above bare soil $(\mathrm{LAI} \leq 0.01)$, and (dashed line) rain events occurring above soil with vegetation canopy $(\mathrm{LAI}>0.01)$.

\subsection{Simulated surface response to a rain event}

The two stages of EF evolution, immediate response and surface recovery, are analysed with the same method used for the observations. However, one must keep in mind the difference of horizontal resolution (less than $1 \mathrm{~km}$ footprint for the measurements, and $0.5^{\circ}$ square for the ALMIP models) and also the larger statistical sample for the models ( 2 to 3 years for the observations and 6 years for the ALMIP models).

\subsubsection{Immediate surface response}

The immediate surface response as a function of soil moisture is illustrated for three of the nine LSMs in Fig. 9 for Djougou, Niamey and Hombori. The three simulations have been chosen to represent the diversity of the simulated surface response.

Whilst the relationship between observed immediate response and soil water content is similar from site to site (Fig. 6), it can be very different between the LSMs for a given 
(a)

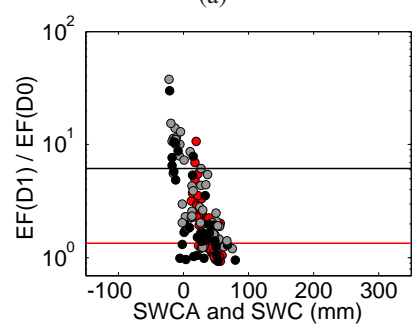

(d)

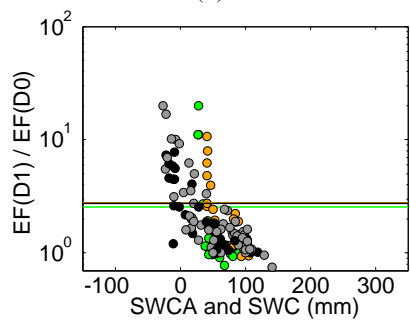

(g)

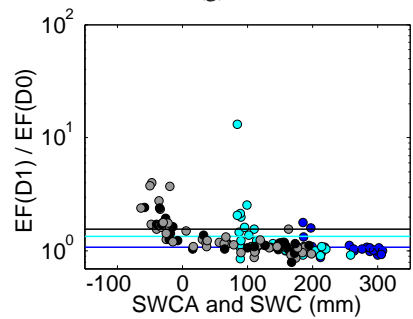

(b)

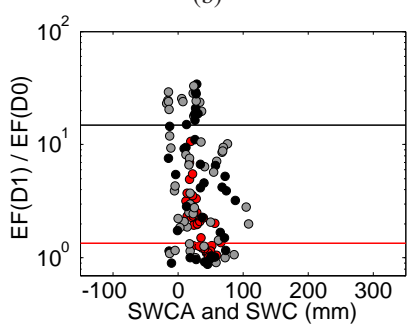

(e)

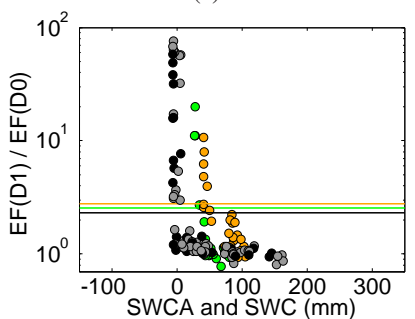

(h)

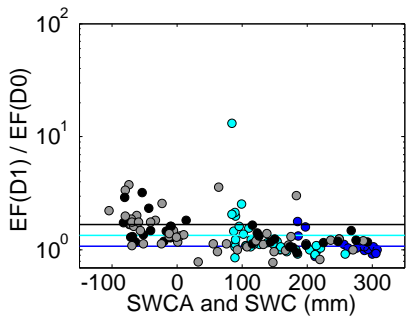

(c)

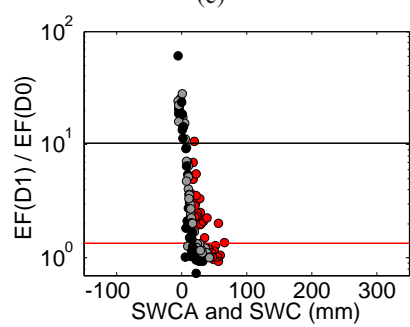

(f)

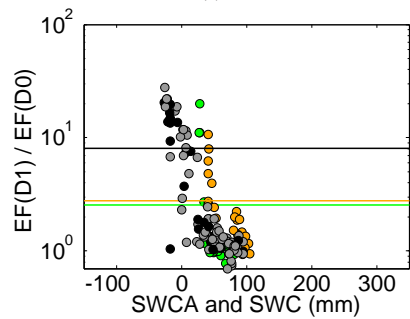

(i)

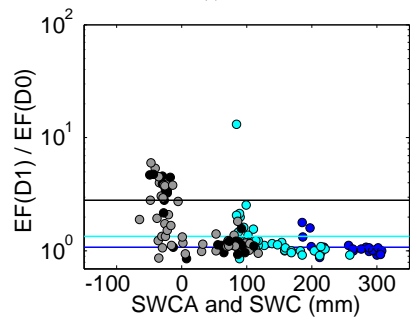

Fig. 9. Example of simulated surface immediate response $(\operatorname{EF}(D 1) / \operatorname{EF}(D 0))$ against SWCA just before the rain, for (a-c) Hombori, (d-f) Niamey and (g-i) Djougou locations with three of the nine LSMs involved in ALMIP (left, middle and right panels are for NOAH, HTESSEL and $\mathrm{SsiB}$, respectively). Grey and dark circles are for cumulated rainfall $\leq 8 \mathrm{~mm}$ and $>8 \mathrm{~mm}$, respectively. Coloured circles are for observed surface immediate response against SWC at (a-c) Mali site, (d-f) Niger sites and (g-i) Benin sites (already presented in 6). Horizontal coloured and black lines stand for $\operatorname{EF}(D 1) / \operatorname{EF}(D 0)$ upper quartile for the measurements and the simulations, respectively.

Table 3. $\tau_{1}$ and $\tau_{2}$, in days, used for the exponential decay of EF after a rainfall.

\begin{tabular}{lcc}
\hline site & $\tau_{1}$ & $\tau_{2}$ \\
\hline ML-grassland bare & $2.9 \pm 0.3$ & $1 \pm 0.01$ \\
ML-grassland vegetated & $6.7 \pm 1$ & $4 \pm 0.2$ \\
NG-fallow bare & $1.3 \pm 0.05$ & $1 \pm 0.01$ \\
NG-fallow vegetated & $21 \pm 3.8$ & $5.5 \pm 1.4$ \\
NG-millet bare & $2.1 \pm 0.2$ & $0.9 \pm 0.04$ \\
NG-millet vegetated & $9.9 \pm 0.6$ & $1.7 \pm 0.3$ \\
BN-fallow vegetated & $10.5 \pm 1.3$ & $1.7 \pm 0.01$ \\
BN-forest vegetated & $74 \pm 55$ & \\
\hline
\end{tabular}

location, and also, between locations for a given LSM. For Djougou, the LSMs are in reasonable agreement with the observations since the surface and vegetation respond very little to rain events, the soil being sufficiently moist within the deep root zone. The differences between LSMs and observations increase for drier soils at higher latitudes where the EF turns out to be very sensitive to evaporation and transpiration schemes. Schüttemeyer et al. (2008) already pointed out the various sensitivities of simulated surface fluxes to soil moisture in comparing HTESSEL and NOAH. At Niamey, the relationship between the surface response and SWCA ranges from an almost linear relationship, as in Fig. 9f (Ssib), to a binary relationship for which the surface does not respond unless SWCA is zero, e.g. Fig. 9e (HTESSEL). At the drier location of Hombori, most of the LSMs exhibit only a weak relationship between immediate response and SWCA.

In addition, the models tend to overestimate the amplitude of the immediate response, particularly at Hombori and Niamey (Fig. 9).

\subsubsection{Surface recovery}

The relationship between the immediate surface response and the amplitude of EF recovery are simulated quite differently by the LSMs. Whereas the relationship in Fig. 10a (NOAH) is similar to the experimental one, the HTESSEL simulation (Fig. 10b) tends to simulate a high EF on D2 with many cases where $\operatorname{EF}(D 2) \approx \operatorname{EF}(D 1)$. This means that a strong increase of EF on $D 1$ is not followed by a decrease of EF on D2 as observed (Fig. 7). In contrast, the LSM in 
Fig. 10c tends to simulate a large decrease of EF on $D 2$ compared to the increase on $D 1$. The model whose results are close to the observed empirical relationship (Fig. 10a) is also the one whose simulated immediate response is clearly linked to SWCA (Fig. 9a, d, g).

The medians of the simulated $\operatorname{EF} / \operatorname{EF}(D 1)$ evolution are estimated by considering separately rain events occurring over bare soil (TR / ET < 0.1) and over vegetation canopies (TR /ET $\geq 0.1$ ) (Fig. 11 left and middle panels, respectively). There is no median evolution of $\mathrm{EF} / \mathrm{EF}(D 1)$ for CLSM and HTESSEL at Djougou since the selected rains never occurred over bare soil in those models at that latitude. Similarly, there is no median evolution of $\mathrm{EF} / \mathrm{EF}(D 1)$ for $\mathrm{SSiB}$ and SWAP at Hombori since the selected rain never occurred over vegetation canopy in those models at that latitude. Consistent with the observations, the simulated decrease of EF between two rain events is more rapid for bare soil than for a vegetation canopy.

There is a relatively good agreement between models for vegetated surfaces, despite the differences between the simulated median evolution of TR / ET ratio. (Fig. 11, right panels). The latter time evolution confirms that evaporation is the main contribution to the surface latent heat flux right after the rain (at $D 1$ ), and then gradually decreases. For HTESSEL, transpiration dominates on all days, yet nonetheless, the surface recovery is similar to the other LSMs.

Estimates of $\tau_{1}$ and $\tau_{2}$ for the observations and the simulated data are presented in Fig. 12. For bare soils (Fig. 12a), $\tau_{1}$ and $\tau_{2}$ values deduced from observations are below 3 days (Table 3), whatever the soil type and the latitude. The values deduced from simulated data vary between 1 and 8 days. The standard deviation of these estimates varies between 0.5 and 1.9 days as a function of the site. This represents a discrepancy between LSMs of 25 to $50 \%$ of the mean value of $\tau$, which is not negligible considering that $\tau_{1}$ and $\tau_{2}$ accuracy is less than $10 \%$ for most of the LSMs (not shown). For vegetation canopies (Fig. 12b), $\tau_{1}$ values deduced from simulated data are in the range of the observations: 7, 10.4 and 43 days at Hombori, Niamey and Djougou respectively. Furthermore, the spread across LSMs for $\tau_{1}$ is only $20 \%$ at Niamey and Hombori. As seen previously, the limit of the method is reached for Djougou, where the 5-day recovery period is too short to accurately estimate such a large exponential coefficient.

\section{Discussion}

Several empirical relationships have been derived from the AMMA-CATCH surface measurements to better describe and understand the way the surface fluxes respond to a rain event over a large range of surface characteristics (soil moisture, vegetation types) along a $\mathrm{S}-\mathrm{N}$ transect in West Africa and throughout the monsoon season. For every site, the amplitude of EF dynamics is largely governed by the soil mois- ture at the seasonal timescale. At the rain event timescale, EF dynamics are ecosystem dependent with around 1 day exponential coefficient for bare soil, below 10 days for annual plants, and above 10 days for perennial plants. As in Teuling et al. (2006), the rooting depth is found to strongly influence the flux recovery after a rain event. The flux stations sample the main types of ecosystems over an aridity transect. Lower exponential coefficients are found at the highest latitudes. Indeed, the southernmost sites are dominated by perennial plants (forest trees, shrubs and young trees in fallows), with deep root systems, which result in a slow decrease of EF after the rain. Conversely, the northernmost sites are dominated by annual plants (grasses, crops), with shallow root systems, leading to a very rapid decrease of EF after the rain. Therefore, EF decays faster in arid zones in West Africa, which does not support previous results (Teuling et al., 2006) that the slower decreases of EF are found at sites that experience the stronger seasonal droughts. The faster EF decay is observed for annual plants along the AMMA south-north transect and such vegetation canopies were not sampled in Teuling's study.

The simulated immediate response of the surface, i.e. the increase in EF the day after the rain, is not as clearly linked to soil moisture (Fig. 9) as it is in the observations (Fig. 7). Furthermore, most of the LSMs tend to overestimate the EF increase after the rain, particularly at the drier sites. Because the EF increase on $D 1$ is mainly due to an increase in evaporation, reasons to explain this overestimation by the LSMs include an excess of interception or limited drainage. In addition, the decrease of simulated EF after $D 1$ for bare soil tends to be too slow (Fig. 12a). These results reveal that modelling bare soil evaporation remains an unresolved issue for LSMs.

On average, the decrease of EF over bare soil is slower in the simulations than observed. On the other hand, over vegetation canopies, simulated and experimental exponential coefficients are in the same range (Fig. 12). Then differences between surface responses over bare soil and vegetation cover might be weaker in the simulations than they are in reality. These shortcomings will affect the ability of an LSM to feed back on deep convection in coupled simulations.

The dispersion of the exponential coefficient values among LSMs shows how the different schemes can speed or slow EF decrease throughout the drying period. The dispersion is particularly important in two cases: (1) over bare soil and (2) over grid points encompassing different vegetation types.

\section{Conclusions}

Several years of surface-atmosphere exchange measurements, over different vegetation types, at different latitudes in West Africa were acquired during the AMMA experiment. The measured EF, soil moisture and leaf area index give a good description of the evolution of the surface and the energy flux partitioning after a rain event, throughout the 
(a)

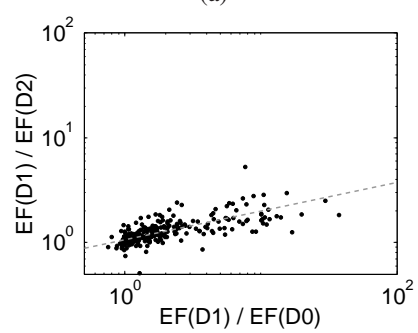

(b)

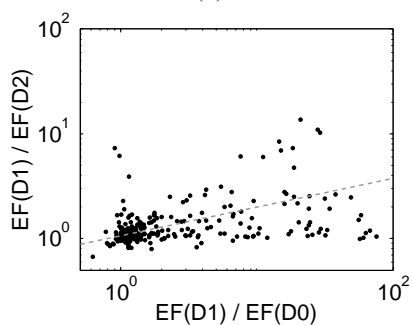

(c)

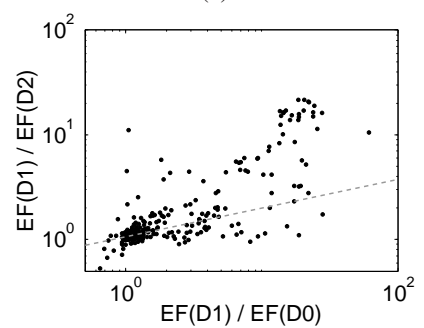

Fig. 10. Immediate surface response $(\operatorname{EF}(D 1) / \operatorname{EF}(D 0))$ against $\operatorname{EF}(D 1) / \operatorname{EF}(D 2)$ simulated by three LSMs (a NOAH, (b) HTESSEL and (c) $\mathrm{SSiB}$ ) at the three locations. The dashed line stands for the observed relationship (Fig. 7).

(a)

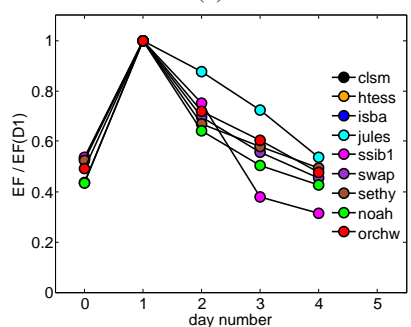

(d)

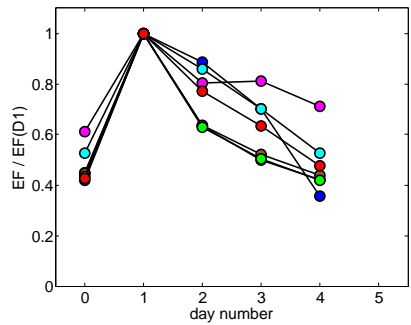

(g)

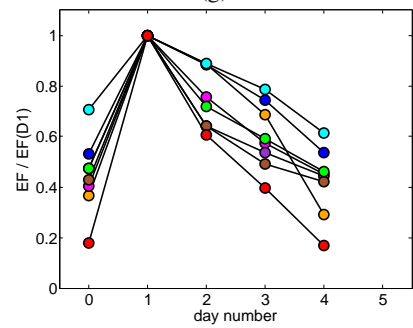

(b)

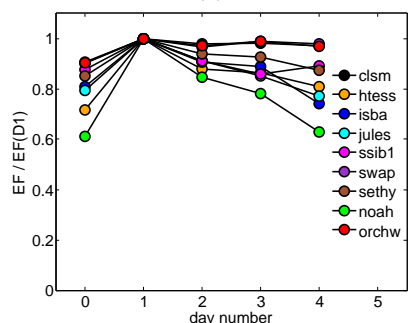

(e)

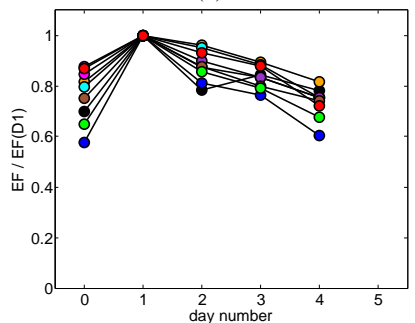

(h)

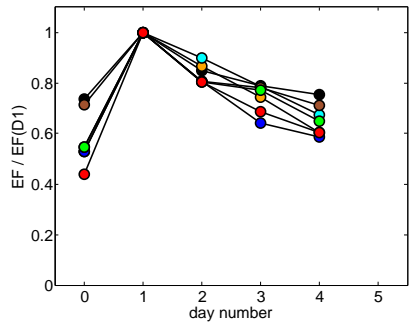

(c)

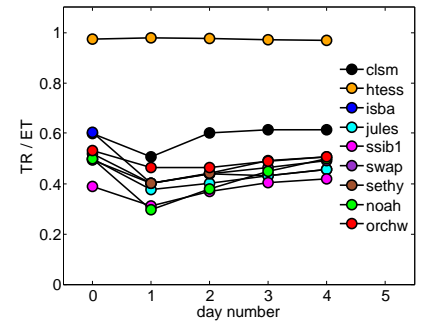

(f)

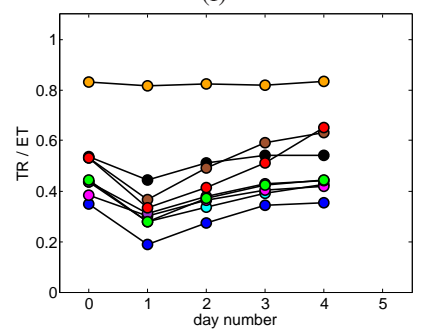

(i)

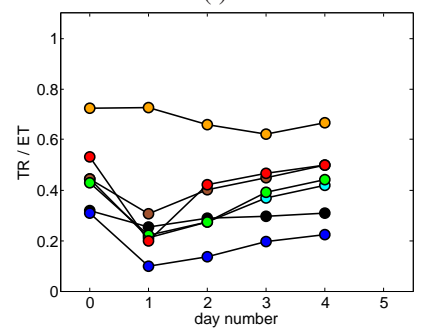

Fig. 11. Median evolution of normalized EF (left panels) over bare soil, (middle panels) over vegetated surface and (right panels) median evolution of transpiration to evapotranspiration ratio (TR/ET) over vegetated surface from day 0 to day 4 in $(\mathbf{a}-\mathbf{c})$ Hombori, (d-f) Niamey and (g-i) Djougou. The colours stand for the nine LSMs.

monsoon, over bare soil and vegetation canopies (fallow and forest in Benin, fallow and millet in Niger and grassland in Mali). In complement to the AMMA experiment, the ALMIP project provides several years of LSM simulations.

In this study, the surface response is split into two stages: (1) the immediate surface response which corresponds to EF increase right after the rain and (2) the surface recovery period during which the $\mathrm{EF}$ decreases with time.

The observational analysis shows that the soil water content before the rain mainly determines the amplitude of the immediate surface response: the lower the soil moisture, the higher the response. Large surface responses are often observed at the beginning of the monsoon when the soil moisture reaches its annual minimum value. The observed relationship between immediate surface response and soil moisture is very similar from site to site, independent of the latitude. This is not the case for the simulations. The relationship, when it exists, is LSM and latitude dependent. Furthermore, the increase in EF after the rain tends to be overestimated by the LSMs.

The decrease of the experimental EF during the dry period is modelled by two exponential relationships previously 
(a)

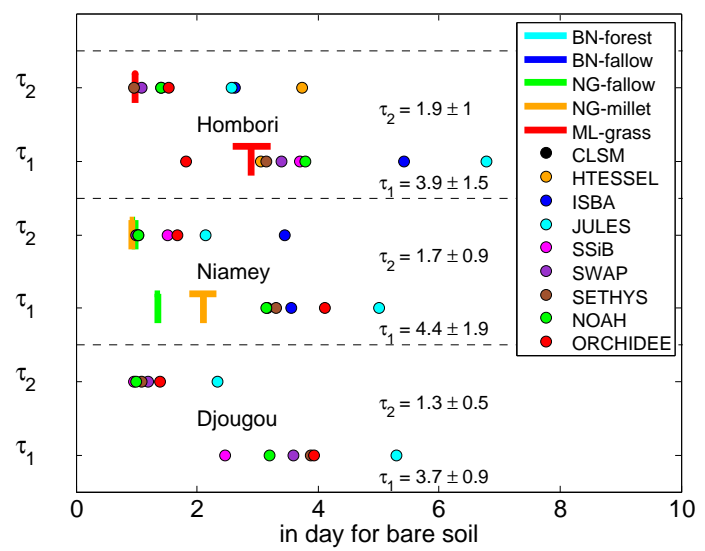

(b)

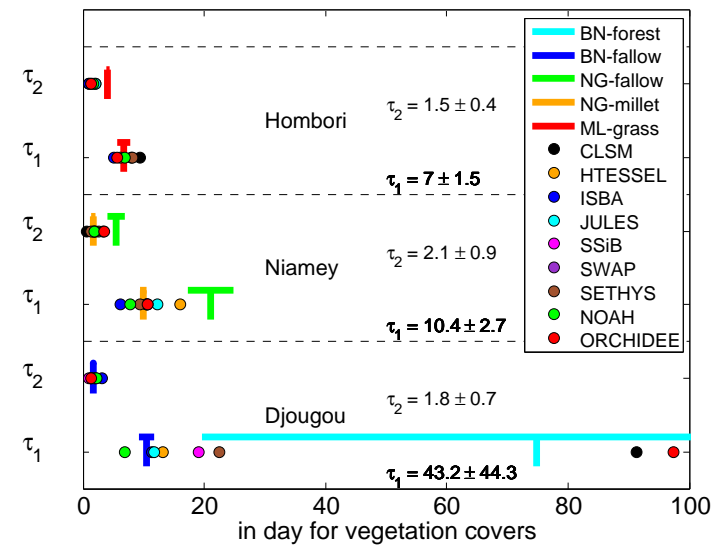

Fig. 12. $\tau_{1}$ and $\tau_{2}$ for measurements and simulated data at the three locations for (a) bare soil and (b) vegetation canopies. Horizontal lines for the experimental values indicate the accuracy of $\tau$ estimate. Mean and standard deviation of $\tau$ estimated by LSM are indicated for each site.

used by Hunt et al. (2002), Kurc and Small (2004) and Teuling et al. (2006). The EF over bare soil has been shown to decrease with a 1.0-2.9 day exponential coefficient at the Niger and Mali sites. The exponential coefficients for vegetation covers are higher, varying between 7 days for the grassland and 74 days for the forest. The functional type of the dominant plants proved to be critical for the surface recovery, in particular the density of perennial plants (shrubs, trees). In the simulations, the decrease in EF over bare soil is less well simulated than over vegetation canopies, with an overestimation and a high dispersion of the exponential coefficient.

The detailed study of LSM simulation of surface response to rain events points out some LSM weaknesses. The repetition of poorly simulated sequences may lead to differences in the annual water and energy budget of LSM. The depiction of bare soil evaporation appears to be a key weakness which leads to a lack of relationship between surface response and soil moisture and to LSM disparity during the drying period.
Acknowledgements. This work was supported by the AMMA project. AMMA was built by an international scientific group and was funded by a large number of agencies, especially from France, UK, the United States and Africa. Field data were collected by the Service d'Observation AMMA-CATCH (http://www.amma-catch.org).

Edited by: J. Rinne

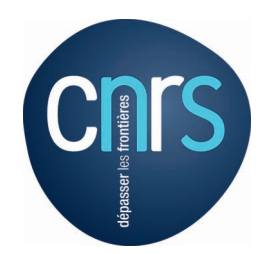

The publication of this article is financed by CNRS-INSU.

\section{References}

Balsamo, G., Viterbo, P. A., Beljaars, A., van den Hurk, B., Hirschi, M., Betts, A. K., and Scipal, K.: A Revised Hydrology for the ECMWF Model: Verification from Field Site to Terrestrial Water Storage and Impact in the Integrated Forecast System, J. Hydrometeorol., 10, 623-643, doi:10.1175/2008JHM1068.1, 2009.

Boone, A., Masson, V., Meyers, T., and Noilhan, J.: The Influence of the Inclusion of Soil Freezing on Simulations by a SoilVegetation-Atmosphere Transfer Scheme, J. Appl. Meteorol., 39, 1544-1569, 2000.

Boone, A., De Rosnay, P., Balsamo, G., Beljaars, A., Chopin, F., Decharme, B., Ducharne, A., Gascoin, S., Grippa, M., Guichard, F., Gusev, Y., Harris, P., Jarlan, L., Kergoat, L., Mougin, E., Nasonova, O., Norgaard, A., Orgeval, T., Ottlé, C., PoccardLeclerc, I., Polcher, J., Sandholt, I., Saux-Picard, S., Taylor, C., and Xue, Y.: The AMMA LAnd SurfAce ModeL inTercoMpAriSon projecT (ALMip), B. Am. Meteorol. Soc., 90, 1865-1880, doi:10.1175/2009BAMS2786.1, 2009.

Boulain, N., Cappelaere, B., Ramier, D., Issoufou, H. B. A., Halilou, O., Seghieri, J., Guillemin, F., Oï, M., Gignoux, J., and Timouk, F.: Towards an understanding of coupled physical and biological processes in the cultivated Sahel -2 . Vegetation and carbon dynamics, J. Hydrol., 375, 190-203, doi:10.1016/j.jhydrol.2008.11.045, 2009.

Cappelaere, B., Descroix, L., Lebel, T., Boulain, N., Ramier, D., Laurent, J., Favreau, G., Boubkraoui, S., Boucher, M., Moussa, I. B., Chaffard, V., Hiernaux, P., Issoufou, H. B. A., Breton, E. L., Mamadou, I., Nazoumou, Y., Oi, M., Ottlé, C., and Quantin, G.: The AMMA-CATCH experiment in the cultivated Sahelian area of south-west Niger - Investigating water cycle response to a fluctuating climate and changing environment, J. Hydrol., 375, 34-51, doi:10.1016/j.jhydrol.2009.06.021, 2009.

Crago, R. D. and Qualls, R.: The value of intuitive concepts in evaporation research, Water Resour. Res., 49, 6100-6104, doi:10.1002/wrcr.20420, 2013.

D'Amato, N. and Lebel, T.: On the characteristics of the rainfall events in the sahel with a view to the analysis of climatic variability, Int. J. Climatol., 18, 955-974, 1998.

de Rosnay, P., Gruhier, C., Timouk, F., Baup, F., Mougin, E., Hiernaux, P., Kergoat, L., and LeDantec, V.: Multi-scale soil moisture 
measurements at the Gourma meso-scale site in Mali, J. Hydrol., 375, 241-252, doi:10.1016/j.jhydrol.2009.01.015, 2009.

Decharme, B.: Influence of runoff parameterization on continental hydrology: Comparison between the Noah and the ISBA land surface models, J. Geophys. Res., 112, D19108, doi:10.1029/2007JD008463, 2007.

Desborough, C. E., Pitman, A. J., and Irannejad, P.: Analysis of the relationship between bare soil evaporation and soil moisture simulated by 13 land surface schemes for a simple non-vegetated site, Global Planet. Change, 13, 47-56, 1996.

d'Orgeval, T., Polcher, J., and de Rosnay, P.: Sensitivity of the West African hydrological cycle in ORCHIDEE to infiltration processes, Hydrol. Earth Syst. Sci., 12, 1387-1401, doi:10.5194/hess-12-1387-2008, 2008.

Dugas, W. A., Hicks, R. A., and Gibbens, R. P.: Structure and function of C 3 and C 4 Chihuahuan Desert plant communities. Energy balance components, J. Arid Environ., 34, 63-79, 1996.

Eltahir, E. A. B. and Gong, C.: Dynamics of Wet and Dry Years in West Africa, J. Climate, 9, 1030-1042, 1996.

Essery, R. L. H., Best, M. L., Betts, A. K., Cox, P. M., and Taylor, C. M.: Explicit Representation of Subgrid Heterogeneity in a GCM Land Surface Scheme, J. Hydrometeorol., 4, 530-543, 2003.

Favreau, G., Cappelaere, B., Massuel, S., Leblanc, M., Boucher, M., Boulain, N., and Leduc, C.: Land clearing, climate variability, and water resources increase in semiarid southwest Niger: A review, Water Resour. Res., 45, 1-18, doi:10.1029/2007WR006785, 2009.

Frappart, F., Hiernaux, P., Guichard, F., Mougin, E., Kergoat, L., Arjounin, M., Lavenu, F., Koité, M., Paturel, J.E., and Lebel, T.: Rainfall regime across the Sahel band in the Gourma region, Mali, J. Hydrol., 375, 128-142, doi:10.1016/j.jhydrol.2009.03.007, 2009.

Gash, J., Kabat, P., Monteny, B., Amadou, M., Bessemoulin, P., Billing, H., Blyth, E., DeBruin, H. a. R., Elbers, J., Friborg, T., Harrison, G., Holwill, C., Lloyd, C., Lhomme, J.-P., Moncrieff, J., Puech, D., Soegaard, H., Taupin, J., Tuzet, A., and Verhoeff, A.: The variability of evaporation during the HAPEX-Sahel Intensive Observation Period, J. Hydrol., 189, 385-399, 1997.

Grippa, M., Kergoat, L., Frappart, F., Araud, Q., Boone, A., de Rosnay, P., J.-M, L., Gascoin, S., Balsamo, G., Ottlé, C., Decharme, B., Saux-Picart, S., and Ramillien, G.: Land water storage variability over West Africa estimated by Gravity Recovery and Climate Experiment (GRACE) and land surface models, Water Resour. Res., 47, 1-18, doi:10.1029/2009WR008856, 2011.

Guichard, F., Asencio, N., Peugeot, C., Bock, O., Redelsperger, J.L., Cui, X., Garvert, M., Lamptey, B., Orlandi, E., Sander, J., Fierli, F., Gaertner, M. A., Jones, S. C., Lafore, J.-P., Morse, A., Nuret, M., Boone, A., Balsamo, G., de Rosnay, P., Decharme, B., Harris, P. P., and Bergès, J.-C.: An Intercomparison of Simulated Rainfall and Evapotranspiration Associated with a Mesoscale Convective System over West Africa, Weather Forecast., 25, 3760, doi:10.1175/2009WAF2222250.1, 2010.

Gusev, E. M., Nasonova, O. N., and Kovalev, E. E.: Modeling the components of heat and water balance for the land surface of the globe, Water Resour., 33, 616-627, 2006.

Guyot, A., Cohard, J.-m., Anquetin, S., Galle, S., and Lloyd, C. R.: Combined analysis of energy and water balances to estimate la- tent heat flux of a sudanian small catchment, J. Hydrol., 375, 227-240, doi:10.1016/j.jhydrol.2008.12.027, 2009.

Huffman, G. J., Adler, R. F., Bolvin, D. T., Gu, G., Nelkin, E., J., Bowman, K. P., Hong, Y., Stocker, E. F., and Wolff, D. B.: The TRMM Multisatellite Precipitation Analysis (TMPA): Quasi-Global, Multiyear, Combined-Sensor Precipitation Estimates at Fine Scales, J. Hydrometeorol., 8, 38-55, doi:10.1175/JHM560.1, 2007.

Hunt, J., Kelliher, F., McSeveny, T., and Byers, J.: Evaporation and carbon dioxide exchange between the atmosphere and a tussock grassland during a summer drought, Agr. Forest Meteorol., 111, 65-82, doi:10.1016/S0168-1923(02)00006-0, 2002.

Koster, R. D., Suarez, M. J., Ducharne, A., Stieglitz, M., and Kumar, P.: A catchment-based approach to modeling land surface, J. Geophys. Res., 105, 24809-24822, 2000.

Koster, R. D., Dirmeyer, P. a., Guo, Z., Bonan, G., Chan, E., Cox, P., Gordon, C. T., Kanae, S., Kowalczyk, E., Lawrence, D., Liu, P., Lu, C.-H., Malyshev, S., McAvaney, B., Mitchell, K., Mocko, D., Oki, T., Oleson, K., Pitman, A., Sud, Y. C., Taylor, C. M., Verseghy, D., Vasic, R., Xue, Y., and Yamada, T.: Regions of strong coupling between soil moisture and precipitation., Science, 305, 1138-40, doi:10.1126/science.1100217, 2004.

Kurc, S. A. and Small, E. E.: Dynamics of evapotranspiration in semiarid grassland and shrubland ecosystems during the summer monsoon season, central New Mexico, Water Resour. Res., 40, 1-15, doi:10.1029/2004WR003068, 2004.

Lebel, T., Cappelaere, B., Galle, S., Hanan, N., Kergoat, L., Levis, S., Vieux, B., Descroix, L., Gosset, M., Mougin, E., Peugeot, C., and Seguis, L.: AMMA-CATCH studies in the Sahelian region of West-Africa: An overview, J. Hydrol., 375, 3-13, doi:10.1016/j.jhydrol.2009.03.020, 2009.

Lohmann, D. and Wood, E. F.: Timescales of land surface evapotranspiration response in the PILPS phase 2(c), Global Planet. Change, 38, 81-91, doi:10.1016/S0921-8181(03)00007-9, 2003.

Lohou, F., Saïd, F., Lothon, M., Durand, P., and Serça, D.: Impact of Boundary-Layer Processes on Near-Surface Turbulence Within the West African Monsoon, Bound.-Lay. Meteorol., 136, 1-23, doi:10.1007/s10546-010-9493-0, 2010.

Masson, V., Champeaux, J., Chauvin, F., Meriguet, C., and Lacaze, R.: A Global Database of Land Surface Parameters at 1-km Resolution in Meteorological and Climate Models, J. Climate, 16, 1261-1282, 2003.

Mauder, M. and Foken, T.: Documentation and Instruction Manual of the Eddy Covariance Software Package TK2, Tech. Rep., University of Bayreuth, Dept. of Micrometeorology, http://opus.ub. uni-bayreuth.de/volltexte/2011/800/ (last access: 15 April 2014), 2004.

Mougin, E., Hiernaux, P., Kergoat, L., Grippa, M., Rosnay, P. D., Timouk, F., Dantec, V. L., Demarez, V., Lavenu, F., Arjounin, M., Lebel, T., Soumaguel, N., Ceschia, E., Mougenot, B., Baup, F., Frappart, F., Frison, P. L., Gardelle, J., Gruhier, C., Jarlan, L., Mangiarotti, S., Sanou, B., Tracol, Y., Guichard, F., Trichon, V., Diarra, L., Soumaré, A., Koité, M., Dembélé, F., Lloyd, C., Hanan, N. P., Damesin, C., Delon, C., Serça, D., Seghieri, J., Becerra, S., Dia, H., Gangneron, F., and Mazzega, P.: The AMMA-CATCH Gourma observatory site in Mali: Relating climatic variations to changes in vegetation, surface hydrology, fluxes and natural resources, J. Hydrol., 375, 14-33, doi:10.1016/j.jhydrol.2009.06.045, 2009. 
Nicholson, S. E.: The West African Sahel: A Review of Recent Studies on the Rainfall Regime and Its Interannual Variability, ISRN Meteorology, 2013, 1-32, doi:10.1155/2013/453521, 2013.

Ramier, D., Boulain, N., Cappelaere, B., Timouk, F., Rabanit, M., Lloyd, C. R., Boubkraoui, S., Métayer, F., Descroix, L., and Wawrzyniak, V.: Towards an understanding of coupled physical and biological processes in the cultivated Sahel - 1. Energy and water, J. Hydrol., 375, 204-216, doi:10.1016/j.jhydrol.2008.12.002, 2009.

Redelsperger, J.-L., Thorncroft, C. D., Diedhiou, A., Lebel, T., Parker, D. J., and Polcher, J.: African monsoon multidisciplinary analysis, B. Am. Meteorol. Soc., 87, 1739-1746, doi:10.1175/BAMS-87-12-1739, 2006.

Saux-Picart, S., Ottlé, C., Decharme, B., André, C., Zribi, M., Perrier, A., Coudert, B., Boulain, N., Cappelaere, B., Descroix, L., and Ramier, D.: Water and energy budgets simulation over the AMMA-Niger super-site spatially constrained with remote sensing data, J. Hydrol., 375, 287-295, doi:10.1016/j.jhydrol.2008.12.023, 2009.

Schüttemeyer, D., Moene, A. F., Holtslag, A. A. M., and de Bruin, H. A. R.: Evaluation of Two Land Surface Schemes Used in Terrains of Increasing Aridity in West Africa, J. Hydrometeorol., 9, 173-193, doi:10.1175/2007JHM797.1, 2008.

Schwendike, J., Kalthoff, N., and Kohler, M.: The impact of mesoscale convective systems on the surface and boundarylayer structure in West Africa: Case-studies from the AMMA campaign 2006, Q. J. Roy. Meteor. Soc., 136, 566-582, doi:10.1002/qj.599, 2010.

Seneviratne, S. I., Lüthi, D., Litschi, M., and Schär, C.: Landatmosphere coupling and climate change in Europe, Nature, 443, 205-209, 2006.

Seneviratne, S. I., Corti, T., Davin, E. L., Hirschi, M., Jaeger, E. B., Lehner, I., Orlowsky, B., and Teuling, A. J.: Investigating soil moisture-climate interactions in a changing climate: A review, Earth-Science Reviews, 99, 125-161, doi:10.1016/j.earscirev.2010.02.004, 2010.

Taylor, C. M., Gounou, A., Guichard, F., Harris, P. P., Ellis, R. J., Couvreux, F., and Kauwe, M. D.: Frequency of Sahelian storm initiation enhanced over mesoscale soil-moisture patterns, Nat. Geosci., 4, 430-433, doi:10.1038/ngeo1173, 2011a.
Taylor, C. M., Parker, D. J., Kalthoff, N., Gaertner, M. A., Philippon, N., Bastin, S., Harris, P. P., Boone, A., Agusti-panareda, A., Baldi, M., Cerlini, P., Descroix, L., Flamant, C., Grandpeix, J.-Y., and Polcher, J.: New perspectives on land-atmosphere feedbacks from the African Monsoon Multidisciplinary Analysis, Atmos. Sci. Lett., 44, 38-44, doi:10.1002/asl.336, 2011 b.

Taylor, C. M., de Jeu, R. A. M., Guichard, F., Harris, P. P., and Dorigo, W. A.: Afternoon rain more likely over drier soils, Nature, 489, 423-426, doi:10.1038/nature11377, 2012.

Teuling, A. J., Seneviratne, S. I., Williams, C., and Troch, P. A.: Observed timescales of evapotranspiration response to soil moisture, Geophys. Res. Lett., 33, L23403, doi:10.1029/2006GL028178, 2006.

Teuling, A. J., Hirschi, M., Ohmura, A., Wild, M., Reichstein, M., Ciais, P., Buchmann, N., Ammann, C., Montagnani, L., Richardson, A. D., Wohlfahrt, G., Seneviratne, S. I., Mauder, M., and Foken, T.: A regional perspective on trends in continental evaporation, Geophys. Res. Lett., 36, L02404, doi:10.1029/2008GL036584, 2009.

Timouk, F., Kergoat, L., Mougin, E., Lloyd, C., Ceschia, E., Cohard, J.-M., Rosnay, P. D., Hiernaux, P., Demarez, V., and Taylor, C.: Response of surface energy balance to water regime and vegetation development in a Sahelian landscape, J. Hydrol., 375, 178-189, doi:10.1016/j.jhydrol.2009.04.022, 2009.

Wallace, J. and Holwill, C.: Soil evaporation from tigerbush in south-west Niger, J. Hydrol., 188-189, 426-442, doi:10.1016/S0022-1694(96)03185-X, 1997.

Xue, Y., Sellers, P. J., Kinter, J., and Shukla, J.: A Simplified Biosphere Model for Global Climate Studies, J. Climate, 4, 345-364, 1991.

Zeng, N., Neelin, J. D., Lau, K.-M., and Tucker, J.: Enhancement of Interdecadal Climate Variability in the Sahel by Vegetation Interaction, Science, 286, 1537-1540, doi:10.1126/science.286.5444.1537, 1999. 